\title{
Planning and Balancing of Disassembly Systems
}

\author{
Gert Zülch and Rainer Schwarz \\ ifab-Institute of Human and Industrial Engineering, University of Karlsruhe \\ Kaiserstrasse 12, D-76131 Karlsruhe, Germany, \\ WWW homepage: http://www.ifab.uni-karlsruhe.de
}

\begin{abstract}
Legislative changes triggered by the exhaustion of natural resources have increased the importance of disassembly as a form of recycling. The implementation of computer-supported procedures in recycling has become indispensable. Time management data was used to develop a tool for the economic planning of disassembly processes, allowing for load balancing of disassembly systems with division of work.
\end{abstract}

\section{Motivation for Disassembly Planning}

The European Union has defined binding guidelines for the prevention and disposal of waste, which must be implemented by the member states into national legislation within a limited period of time. As a result, several new laws have been passed in Germany in the last few years requiring manufacturers and importers to take back the devices they produce at the end of their lifecycle and to re-integrate them into the material cycle.

The expected increase in the return of used products will force manufacturers to optimize the disassembly of used products in order to re-integrate the involved raw materials into the production cycle as secondary raw materials or secondary products or to dispose of materials in an appropriate manner [1]. When recycling used products the objective is always to disassemble the reusable parts without damaging them. Thus, new approaches are necessary to solve impending organizational problems and a demand for new tools is at hand. In addition to their applications in the field of disassembly, these tools can also be beneficial in the service area, especially for the maintenance of products.

The proportion of manual and (semi-)automated disassembly systems is also of substantial importance in the service area for the maintenance of products $[2,3]$. In the future, the disassembly of used products will take on an even more industrial

Please use the following format when citing this chapter:

Zülch, G. and Schwarz R., 2008, in IFIP International Federation for Information Processing, Volume 257, Lean Business Systems and Beyond, Tomasz Koch, ed.; (Boston: Springer), pp. 49-56. 
character, whereby the economical design and control of disassembly processes will be of primary importance.

\section{Disassembly Planning Procedure with Load Balancing}

\subsection{Tasks of Disassembly Planning}

The objective of disassembly planning is to create an organizational, staff and techniques foundation for the ergonomic and economic separation of used products into their constituent parts. In addition to defining the disassembly tasks, the planning of a disassembly system comprises creating a suitable sequence and materials plan. This includes the structuring of used products, the creation of disassembly work plans, the definition of the separation procedures, the disassembly depth, the number of needed workplaces, the selection of equipment, the flow of materials system and many more(cf. [4], pp. 245-253).

Disassembly is by no means a mere reversal of the assembly. In contrast to assembly, in which e.g. all parts are defined geometrically and are in the same qualitative state, disassembly must also take into consideration the fact that each used product has been subject to a diversity of influences throughout its lifecycle (corrosion, wear, deformation etc.) and is thus in a different state when it comes to recycling. Therefore, stochastic influences, which make planned disassembly sequences unpredictable, must be taken into account during the planning of disassembly processes (e.g. the selection of separation procedures) and the determination of disassembly operation times [1]. This lends great significance to time management evaluations (cf. [5], pp. 147-156].

\subsection{Scope of Investigations}

In the field of recycling, the application of computer-supported procedures has become an indispensable necessity. A computer-aided procedure supporting the planning of disassembly systems has been developed at the ifab-Institute of Human and Industrial Engineering at the University of Karlsruhe within the context of a project supported by the German Research Association (DFG - Deutsche Forschungsgemeinschaft).

The developed software tool TANJA (German abbreviation for "Disassembly Planning with Object-oriented Load Balancing") serves to support the planning of economically feasible disassembly processes while also taking the given organizational, personnel and technical conditions into account.

During the development of the procedure, analyses and data gathering (concerning work organization, equipment, applied separation procedures, time data capturing etc.) were carried out in several disassembly enterprises. Time building blocks were created using registered data and MTM standard data for manual disassembly operations (e.g. remove screw connection, apply separation sander etc.) in order to determine the disassembly operation times. The workers' specific, technical disassembly knowledge (work process knowledge) was documented through questioning 
(interviews) and video analyses and was implemented in a help system along with examples of good practice.

\subsection{Characteristics of the Software Tool TANJA}

The software tool TANJA makes it possible to digitally represent operations and resources in a disassembly system, to develop various planning solutions and to compare these to each other. The primary objective during the development of this computer-supported planning tool was to provide disassembly enterprises with a practical assistance for the planning of disassembly systems. The procedure allows the user:

- to structure disassembly processes through disassembly precedence diagrams,

- to assign individual disassembly operations to decoupled work systems,

- to balance the load of the disassembly system based on a pre-determined cycle time or a given number of disassembly stations or workers,

- to carry out an ergonomic assessment of the physical stress to the workers resulting from manual activities,

- to digitally represent the planned disassembly system as well as

- to compare the developed planning solutions based on assessment criteria selected by the user and supported by the software tool.

\subsection{Structural Design of TANJA}

The planning procedure TANJA was conceived for PC implementation. Microsoft Windows XP was chosen as the operating system and the object-oriented programming language Microsoft Visual Basic.net was selected as the development environment. This computer platform allows for a broad spectrum of implementation in industrial disassembly systems. In order to ensure easy use and acceptance, the procedure's functionalities were modelled after prevalent Microsoft Office Software packages (e.g. cut \& copy, drag \& drop, menu structure design etc.).

In TANJA time building blocks developed according to MTM are used for the time management analysis of disassembly operations. For this, data material from earlier research work was taken and supplemented with data collected in disassembly enterprises [6, 7, and 8]. These time building blocks were then used to specify operation times for individual disassembly operations and to allocate them to individual work stations in disassembly systems with division of labour while also taking disassembly-specific influencing factors (corrosion, separation procedures etc.) into account.

The load balancing to be carried out is dependent upon a predetermined cycle time or the number of work stations defined or available in the disassembly workshop. A further module was developed for the description of workplaces, the selection of equipment, buffers, conveyors, collection bins for disassembled parts etc. Further modules for the description of workplaces, the execution of worker stress analyses as well as a help system with examples of good practice were also implemented in TANJA. 
In order to plan a disassembly system, the individual disassembly tasks should be illustrated in an appropriate manner. Modelling, in particular as disassembly precedence diagrams, is particularly well suited for designing possible disassembly operations. In disassembly precedence diagrams nodes and arcs are used to describe the sequence restrictions between the individual disassembly operations in a sort of network. The nodes contain detailed descriptions of the disassembly operations, whereas the arcs define the predecessor-successor relationships between the individual disassembly operations.

With regards to the disassembly of used products, in particular the availability of product data is a specific problem. From experience, disassembly enterprises rarely possess drawings or CAD-data with detailed information, regarding e.g. components, the type of connections between the individual components or about the materials used. The determination of the individual disassembly operations is thus usually carried out through test disassembly runs.

The main steps in the structural planning of a disassembly system are in principle analogous to those in assembly planning [9]. Like in assembly planning, the planning of a disassembly system consists of several consecutive phases: determining the work process principle (e.g. line disassembly), allocating the individual disassembly operations to work systems (pre- disassembly, main and final disassembly) and by carrying out a load balancing. A module was developed for TANJA which can allocate the disassembly operations illustrated in a disassembly precedence diagram to individual disassembly work systems. The selection of these work systems is comparable to the definition of pre-, main and final disassemblies. The classification of the complete disassembly into independent work systems allows the individual disassembly operations to be decoupled, meaning they can be executed in part independently of one another.

\subsection{Planning Disassembly Systems with Division of Labour}

Using the developed software tool TANJA the planning of disassembly systems is carried out in three main steps: Development of the disassembly precedence diagram for a specific product, load balancing of the whole disassembly system and configuration of the layout.

The integration of the time study of the individual disassembly operations into the structure planning is highly advantageous. This was achieved by entering all information relevant to the disassembly contained in the respective nodes of the disassembly precedence diagram developed in the first planning step into the TANJA module ANGELA (German abbreviation for "Planning Tool for Time Study of Manual Disassembly"). Specifically, these are the disassembly operations along with their operation times as well as disassembly operation costs, detailed work plans, tools, materials used etc. This makes a shift of the individual nodes within the pre-, main and final disassembly areas possible without losing information about the details of the individual operation. In this manner all standard disassembly separation procedures necessary for the disassembly of a component can be planned. If ANGELA cannot describe a separation procedure, the planner can then enter an additional time allowance into the system that he deems necessary to cover the 
disassembly time of the non-defined disassembly operation. In the work plan integrated in ANGELA, all the individual work operations, the tools used and any special features of the disassembly are described in text form.

Once the cycle time and the number of work stations have been defined, the load of the disassembly system is balanced automatically, providing results such as e.g. the utilization of the individual work stations. The user can change the automatically generated assignment of disassembly operation to workplaces manually, should he deem this to be necessary.

Dependent upon the selected number of pre-, main and final disassembly areas, the workplaces are automatically grouped in the layout configuration by the planning tool. The complete disassembly system can be visualized by depositing a hall floor plan and supplementing it with symbols (e.g. objects, tools etc.) provided by TANJA. In this manner several planning solutions can be developed and then compared and assessed using assessment criteria contained in TANJA (short lead times, number of workers, activities etc.). They can be weighted by the planner based on an additive preference function.

\section{Practical implications}

The planning procedure has been tested and verified in a disassembly workshop for motorcycles. The task was to plan a motorcycle disassembly with the goal of recovering all reusable parts and components (motor, carburettor, electronic elements etc.) and to break the non-reusable material down into the purest fractions possible.

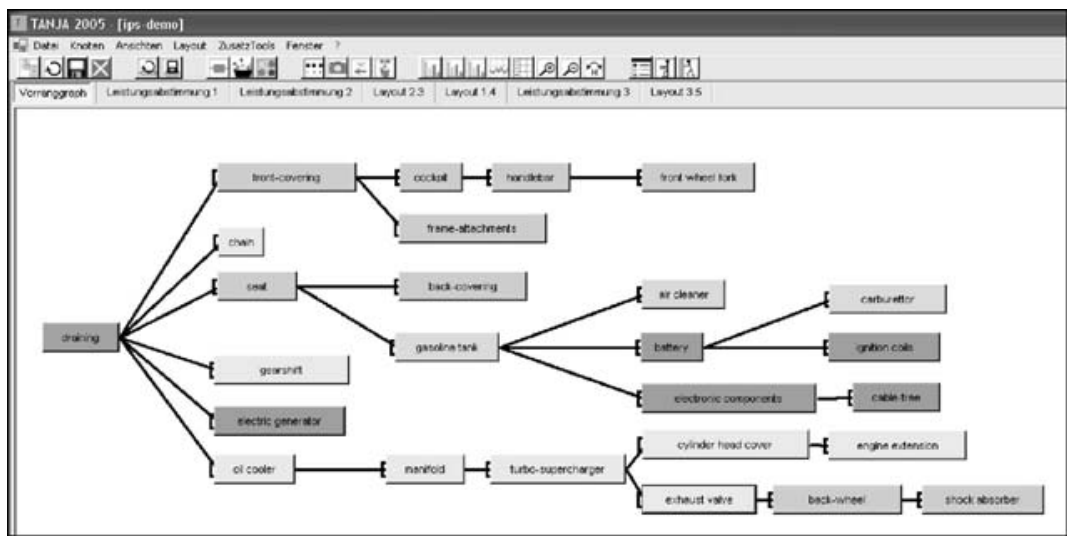

Fig. 1. Disassembly precedence diagram created with TANJA

For this project, several motorcycles of the same model were regarded. The disassembly work was carried out by skilled labourers. First, a test disassembly of a motorcycle was carried out according to the normally applied procedures within the company, whereby the disassembly operation times were recorded and the separation 
procedures, tools, aids, auxiliary activities etc. were documented. Subsequently, a disassembly precedence diagram was generated using drawings of the motorcycle and based on the results of the test disassembly (see Fig. 1). Finally, the disassembly system was re-planned using TANJA.

Next, the data necessary for the disassembly operations for the individual components was entered into the nodes of the disassembly precedence diagram (see Fig. 2). The degree of detail was thereby defined by the planner.

Figure 2 shows some content from the node for the example of the motorcycle front cladding. In addition to general information about the used product and the disassembly components, the disassembly purpose, such as reuse or recycling, is defined since completely differing time building blocks are used for the respective purposes (left-hand part of Fig. 2). The times allocated for recycling are longer than those allocated for reuse since recycling demands a higher degree of purity of the separated material, thus requiring more attention during the disassembly.

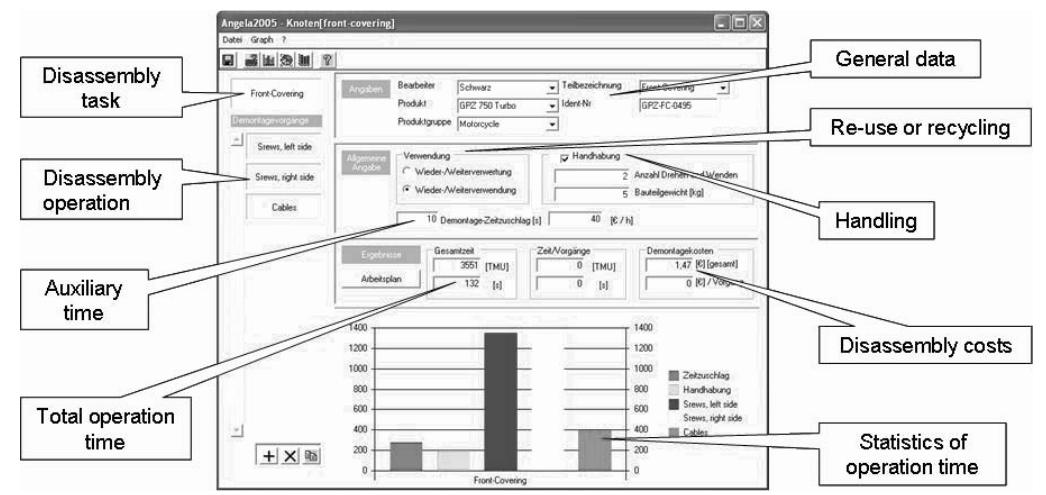

Fig. 2. Time study created with ANGELA

Furthermore the disassembly times of those individual operations necessary for the separation of a component from a used product are determined (right-hand part of Fig. 2). For example, in order to disassemble the full cladding on the left-hand side, the screws first have to be removed. The number of screws, the number of different screw types, the duration of the unscrewing of a single screw (process time) etc. are entered in order for ANGELA to automatically calculate the respective disassembly time. All nodes in the disassembly precedence diagram are processed in this manner in order to generate to total disassembly time of the used product.

The division of the disassembly operations into decoupled work systems (pre-, main and final disassembly) is oriented not only towards the disassembled product, rather also towards the objective of removing certain, valuable components, which are intended for sale as secondary products. In the project case this is due to a typically large demand, from the old product as soon as possible. These components are primarily premium plastic cladding elements, the tank, any electrical components (ignition coil, dynamo etc.) as well as the muffler.

The load balancing was carried out based on the conditions of the existing workshop. It resulted in three work systems with a total of five workplaces (cf. Fig. 3). 


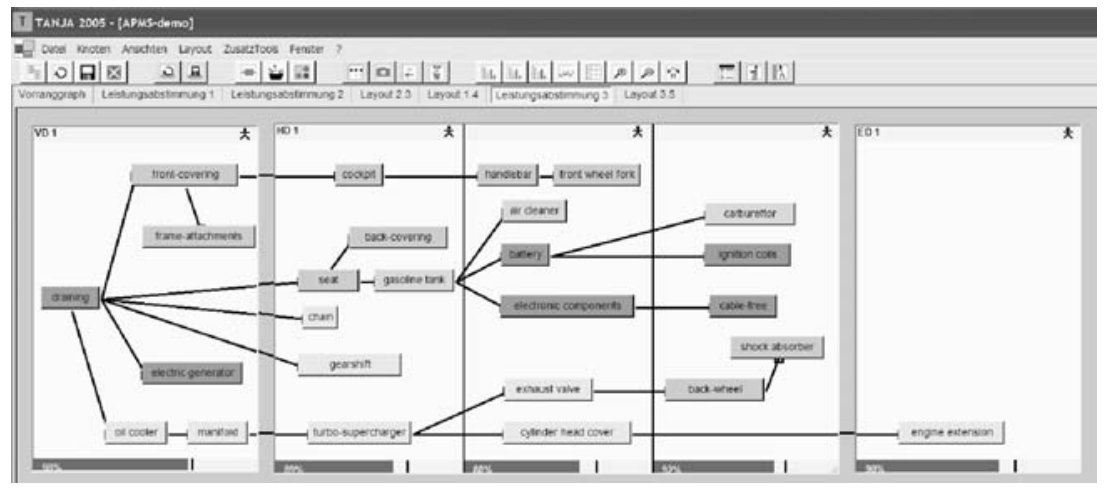

Fig. 3. Disassembly load balancing created with TANJA

The realignment of disassembly operation sequences, the implementation of alternative separation techniques, the provision of additional tools at various spots around the motorcycle and the resulting significant reduction of throughput times etc. brought about a reduction of the total disassembly time of $40 \%$ compared with the conventional procedure.

\section{Aspects of Future Research}

TANJA is a new procedure which uses time study to make load balancing in disassembly systems possible. With TANJA individual workplaces, disassembly group work systems or disassembly lines can be planned and assessed.

During the research project it was confirmed that disassembly enterprises are in great need of an adequate planning procedure and a time study of disassembly processes. Furthermore, it is imperative for these enterprises not only to plan the disassembly operations to be executed which are characterized by stochastically occurring situations, rather also to control the running operations.

Due to the unpredictability of disassembly operations a procedure for controlling disassembly systems must be able to react quickly to unscheduled activities and disturbances and to intervene in the running system state with appropriate control measures. The following starting points can be defined for the development of such a procedure:

- Planning of order sequences in the disassembly system for used product variants (batch-wise for single products or a total mix of models),

- Simulation of order sequences with stochastic operation times and interruptions,

- Alignment of the disassembly depth dependent upon the disassembly system utilization,

- Varying assignment of disassembly operations to work systems,

- Flexible selection of disassembly procedures, dependent upon the system load,

- Dispatching of different used products to one disassembly line.

A complex planning and control tool which is aligned with the demands of the disassembly by means of proven disassembly operation times can ensure an efficient 
flow of operations within the disassembly system and thus also the economic efficiency of the disassembly system. It would hereby be beneficial to develop an even more complex procedure for disassembly planning and control (DPC) which not only supports the development of new disassembly systems, rather also allows for the improvement of existing ones.

\section{References}

1. Gert Zülch, Reinhard Müller, and Emmerich F. Schiller, Information System for Supporting Manual Disassembly Tasks, in: ICME 2000, The Eighth International Conference on Manufacturing Engineering, edited by Causal Productions (2000), Compact disk, file://D//HTML/ME00S104.HTM.

2. Gert Zülch and Jörg W. Fischer, Increasing the Flexibility of Working Times and Personnel Control in an Industrial Repair Work System, (Espoo, Sim-Serv, 2004) http://www.sim-serv.com/white_papers.php (August 13, 2004).

3. Gert Zülch and Joachim Greinke, Simulation-aided Reconfiguration of an Industrial Service System for the Repair of Electrical Tools (Espoo, Sim-Serv, 2004), http://www.sim-serv.com/white_papers.php (November 05, 2004).

4. Gert Zülch, Emmerich F. Schiller, and Milko Schneck, Adaptive Dynamic Process Plans - A Basis for a Disassembly Information System, in: ECO-Performance '96, edited by Rainer Züst, Gabriel Caduff, and Michael Frei (Zürich, Verlag Industrielle Organisation, 1996), pp. 245-253.

5. Jörg Fischer, Patricia Stock, and Gert Zülch, Simulation of Disassembly and Reassembly Processes with Beta-distributed Operation Times, in: Integrating Human Aspects in Production Management, edited by Gert Zülch, Harinder S. Jagdev, and Patricia Stock (New York, Springer, 2005), pp. 147-156.

6. Olaf Mönig and Rainer Schwarz, Zeitermittlung für die manuelle Demontage, in: Aktuell, das Info-Magazin der Deutschen MTM-Vereinigung, 2(2002), (Hamburg, 2002), pp. 14-15.

7. Gert Zülch and Rainer Schwarz, Demontagesystemplanung an einem Beispiel aus der Elektroindustrie, in: Good Practice. Ergonomie und Arbeitsgestaltung, edited by Kurt Landau (Stuttgart, ergonomia Verlag, 2003), pp. 347-362.

8. Gert Zülch, Reinhard Müller, and Emmerich F. Schiller, A Disassembly Information System, in: Life Cycle Networks, edited by Frank-Lothar Krause and Günther Seliger (London, Weinheim, New York et al., Chapman \& Hall, 1997), pp. 400-412.

9. Wolfgang-Jürgen Braun, Beitrag zur Festlegung von Arbeitsteilung in manuellen Arbeitssystemen (Aachen, Shaker, 1995), p. 26. 